\section{Palliative care}

Edited by Dr Marie Fallon MD FRCP(Glas) FRCP(Ed) MRCGP, Reader in Palliative Medicine, Edinburgh Cancer Centre, Western General Hospital, Edinburgh

\section{Palliation of breathlessness}

Duncan JF Brown MD MRCP, Consultant in Palliative Medicine, St Columba's Hospice, Edinburgh

\section{Clin Med 2006;6:133-6}

Breathlessness (or dyspnoea) is a common symptom in patients with cancer and other advanced progressive illnesses such as cardiac failure, chronic obstructive pulmonary disease (COPD) and pulmonary fibrosis. It is often distressing to both patient and carer. ${ }^{1}$ As death approaches it is a difficult symptom to manage and often not well palliated. Although touching on management of specific causes of breathlessness, this article will mainly focus on the symptomatic management of breathlessness at the end of life.

\section{Definition}

Breathlessness has been defined in various ways including an 'uncomfortable awareness of breathing'2 or 'an uncomfortable and fearful sensation of being unable to breathe.' ${ }^{3}$ Patients use a variety of descriptive terms to talk about their breathlessness which may vary according to the aetiology of the symptom. ${ }^{4}$

\section{Assessment}

Management of breathlessness starts with a good history and examination. It is important to establish the speed of onset of breathlessness, precipitating and relieving factors and its timing: infection, hypoxia, anaemia, bronchospasm or effusion, and may suggest the need for further investigation, including chest X-ray or computed tomography scan.

\section{Management}

The management of some specific causes of breathlessness is outlined in Table $1 .{ }^{5}$ It is important to consider the ethical implications of treatment (ie whether the burdens of treatment outweigh the benefits). For example, it may be possible to tap a pleural effusion, but would the risks of pneumothorax in a patient in the last days of life be worthwhile? A patient with a pulmonary embolism could receive anticoagulation, but do the risks of bleeding outweigh the benefits of treatment?

\section{Symptomatic management}

Many patients with advanced disease have no obvious cause for their breathlessness. Some may have significant respiratory muscle weakness, ${ }^{2}$ possibly due to general weight loss and the muscle deconditioning of advanced illness. Drugs, including corticosteroids, can also tion of pre-existing COPD. Clinical examination may reveal obvious signs of

Table 1. Management of specific causes of breathlessness. ${ }^{5}$

\begin{tabular}{ll} 
Symptom & Management \\
\hline Pleural effusion & Therapeutic pleural aspiration of 1-1.5 litres \\
& Drainage and pleurodesis may be considered (talc is \\
probably most effective agent) & Anticoagulate if appropriate, balancing risks and benefits \\
Pulmonary embolism & LMWH (not warfarin) in last months of life as it is safer \\
Large airway obstruction & Radiotherapy \\
& Endobronchial tumour: debulking or laser therapy may be \\
& possible \\
& Extrinsic compression: stenting may be possible \\
& Trial of steroids (dexamethasone 8-12 mg daily) may be \\
appropriate & Steroids (dexamethasone 8-16 mg daily) \\
Lymphangitis carcinomatosa & Radiotherapy or chemotherapy, depending on histology, may \\
bVCO of significant benefit in some & SVC stenting should be considered, especially if recurrent \\
SVCO & Thrombolytic therapy may be considered if thrombus present \\
Antibiotics, if appropriate & Blood transfusion may be appropriate \\
Enaemia & chemotherapy) \\
&
\end{tabular}

EPO = erythropoietin; LMWH = low molecular weight heparin; SVC = superior vena cava; SVCO = superior vena cava obstruction. 
cause muscle weakness and may need to be stopped or reduced in dose. Some patients may have multiple causes of their breathlessness or interventions for specific causes may have led to only a limited improvement. In these situations a symptomatic approach is key, involving both non-pharmacological and drug-based components.

\section{Non-pharmacological management}

A non-pharmacological approach to management of breathlessness will take into account not only the physical element of the symptom but also the psychological, social and spiritual aspects and may involve different members of the multidisciplinary team. ${ }^{5}$ It will focus on improving the patient's general feeling of well-being and on helping the

\section{Key Points}

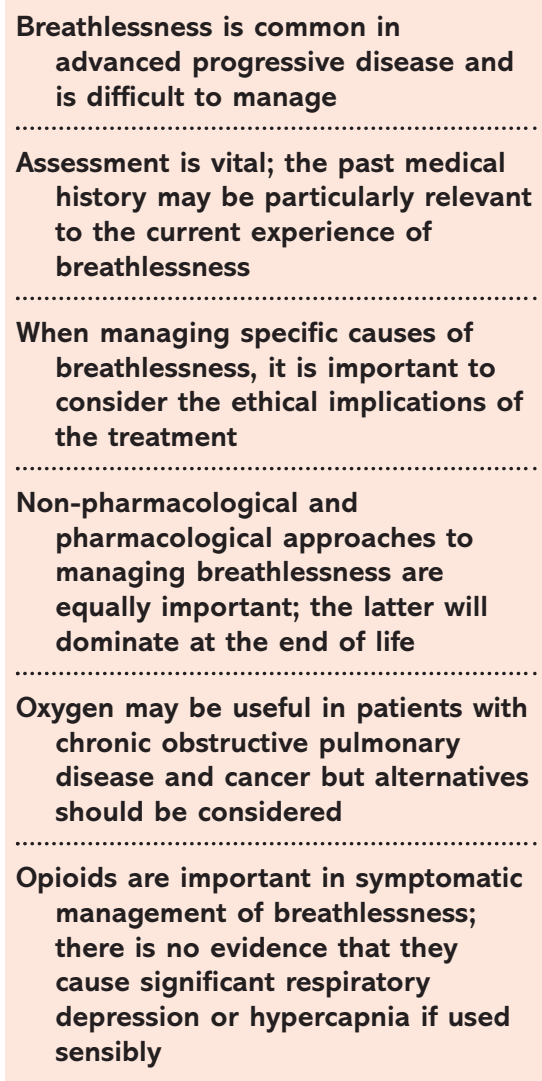

Breathlessness is common in advanced progressive disease and is difficult to manage

Assessment is vital; the past medical history may be particularly relevant to the current experience of breathlessness

When managing specific causes of breathlessness, it is important to consider the ethical implications of the treatment

\section{Non-pharmacological and pharmacological approaches to managing breathlessness are equally important; the latter will dominate at the end of life \\ Oxygen may be useful in patients with chronic obstructive pulmonary disease and cancer but alternatives should be considered \\ Opioids are important in symptomatic management of breathlessness; there is no evidence that they cause significant respiratory depression or hypercapnia if used sensibly}

KEY WORDS: benzodiazepines, breathlessness, cancer, chronic obstructive pulmonary disease, dyspnoea, end of life, opioids, oxygen, palliative care patient regain some control over their breathlessness. This may involve:

- physiotherapy or occupational therapy input for breathing exercises

- advice regarding activity planning and pacing, and

- teaching of relaxation techniques. ${ }^{6}$

Positioning in bed may affect breathing as lying flat can exacerbate breathlessness. Positioning with the good lung down in patients with unilateral pathology may improve the ventilation perfusion ratio and therefore oxygenation. ${ }^{7}$ Limited cognitive therapy may allow the patient to control the negative automatic thoughts (typically 'I'm going to die' during a panic attack) which may increase anxiety and exacerbate breathlessness. Complementary therapies such as acupuncture may be helpful, ${ }^{8}$ although the evidence is limited. There is also some evidence that nurse-led or multidisciplinary breathlessness clinics may be helpful in stabilising or improving breathlessness and quality of life. ${ }^{9,10}$

\section{Pharmacological management}

There are few - and only small - controlled studies of the pharmacological management of breathlessness. Most clinical experience relates to the use of oxygen, opioids, benzodiazepines, nebulised bronchodilators and corticosteroids.

\section{Oxygen therapy}

The use of oxygen for the relief of breathlessness is controversial. There is some evidence for its use in relief of breathlessness in patients with COPD and advanced cancer, ${ }^{11}$ although studies are small and it is difficult to predict which patients will benefit most. In practice, it could be considered in patients with oxygen saturations less than $90 \%$. Even a placebo effect in patients with normal oxygen saturations may be of psychological benefit. However, some patients can become dependent on oxygen. Also, relief of breathlessness may often relate to the movement of air over the patient's face which could equally well be provided by the use of a fan, opening a window or using compressed air instead of oxygen. Some patients find oxygen masks claustrophobic, that they impede talking and eating and cause a dry mouth. These issues are easily remedied at low flow rates of oxygen by nasal cannulae which are generally well tolerated. Care is necessary in patients with type II respiratory failure as higher flow rates may cause increasing hypercapnia. $^{11}$

\section{Opioids}

The use of opioids in the management of breathlessness is often feared by clinicians who worry about causing respiratory depression, especially in patients with COPD. ${ }^{12}$ When given for breathlessness, opioids may reduce minute ventilation, ${ }^{5,13}$ but there is no evidence that careful use of opioids has a clinically significant negative effect on arterial concentrations of oxygen or carbon dioxide. ${ }^{14}$ More caution may be needed in patients with type II respiratory failure but careful opioid titration may well be of benefit with minimal harm. Opioids may also aid breathlessness by reducing the central perception of the symptom, the anxiety associated with breathlessness and sensitivity to hypercapnia. ${ }^{14}$

A systematic review of double-blind, randomised placebo-controlled trials of opioids in the treatment of breathlessness supported the use of both oral and parenteral opioids in patients with advanced disease. ${ }^{14}$ The review mainly covered COPD patients but also included a cancer study and a heart failure study, showing benefit for opioids in all groups. More recent evidence has reported opioids to be of benefit for breathlessness in patients with pulmonary fibrosis. ${ }^{15}$ There is no clear evidence for dosing regimens but a pragmatic approach is outlined in Table 2.

Alternative opioids for patients who cannot tolerate morphine include oxycodone and hydromorphone, although there is no good evidence as yet regarding benefits. Controversy exists over the role of nebulised opioids. A systematic review by Jennings and colleagues ${ }^{14}$ reported no overall benefit although other work has suggested that individual patients may benefit. ${ }^{16}$ 


\section{Anxiolytic therapy}

Anxiety and low mood may exacerbate the distress of breathlessness, ${ }^{17}$ particularly at night when patients often feel isolated and unsupported. There is limited trial evidence but benzodiazepines can be useful for reducing anxiety and hyperventilation; they may also reduce central sensitivity to hypoxia and hypercapnia. ${ }^{5}$ Lorazepam is a useful drug for patients with significant associated panic and can be given as required or regularly. It is shorter acting than diazepam and has the advantage of being administered sublingually $(0.5-1 \mathrm{mg})$ where it dissolves easily (the last thing a patient who is breathless and panicky wishes to do is swallow a tablet!). If the patient is at home, the tablet can be left by the bedside to be taken at night if awakened with a panic attack, restoring some control to the patient. The short-acting parenteral drug midazolam may be useful in the terminal phase and can be given as bolus subcutaneous (sc) injections $(2.5 \mathrm{mg})$ or in a syringe driver
(5-10 mg sc over 24 hours would be a suitable starting dose). Some antidepressants are licensed for panic disorder (eg citalopram) and can be useful adjuncts to management of anxiety/panic. ${ }^{5}$

\section{Other therapeutic measures}

- Nebulised saline may be a helpful aid to expectoration in patients with upper airway secretions or upper respiratory tract infection and may have some effect on breathlessness. ${ }^{16}$

- Corticosteroids may be of benefit in a variety of situations (Table 1 ). If the cause of breathlessness is unclear, a brief trial of oral dexamethasone 4-8 mg can be considered, stopping after four days if there is no improvement.

- There is also some evidence for the use of nebulised furosemide as a treatment for breathlessness in patients with COPD and advanced cancer. ${ }^{18,19}$ It is not clear whether

Table 2. Opioid dosing for symptomatic management of breathlessness.

\section{Opioid naïve patient \\ Opioid naïve, elderly frail patients and those with poor renal function (morphine metabolites will accumulate) \\ If opioids are of benefit}

Stable regular dose

Patients already prescribed regular opioids for pain

Episodes of breathlessness between regular opioid doses

Breathlessness purely related to movement

Care in titration (side effects may be more prevalent than when opioids given for pain)
2-2.5 mg NR morphine sulphate nocte as trial dose If tolerated, 2-2.5 mg NR morphine every 4 hours. Substitute sc morphine $1-1.5 \mathrm{mg}$ if patient cannot swallow

Lower doses than above may be needed. Consider reducing dose frequency to qid

Titrate dose in increments of $25-30 \%$ until maximum effect and minimum side effects

Consider change to long-acting twice daily morphine (eg MST continus: add total dose of regular and prn morphine doses over last 24 hours, divide by 2 and give this dose as MST every 12 hours)

For parenteral (sc) dose divide daily total oral dose by 2 (or 3 in very frail) and give over 24 hours in syringe driver Increase regular dose by $25-30 \%$

If in titration phase of NR morphine, give extra 4 hourly dose

If on stable morphine dose, give NR morphine at $5-15 \%$ of total daily dose

Give morphine $30 \mathrm{~min}$ prior to activity (if given after activity, breathlessness may settle before opioid helps)

Regular opioid may not help

Consider shorter-acting opioid (eg alfentanil)

Side effects: drowsiness, hallucinations, vivid dreams, confusion, myoclonus

$\mathrm{MST}=$ morphine sulphate $($ controlled release); $\mathrm{NR}=$ normal release $; \mathrm{prn}=$ as required; $\mathrm{sc}=$ subcutaneous

single or repeated dosing is most appropriate.

\section{Terminal phase (last 48-72 hours)}

Breathlessness may be an increasing problem as death approaches and the use of a syringe driver with opioid and midazolam delivered by sc infusion may be necessary. Many of the non-pharmacological methods of managing breathlessness are either impossible or difficult in the last few days and, in general, pharmacological treatment is needed.

\section{Conclusions}

Breathlessness is a difficult and distressing symptom to manage at the end of life. A multidisciplinary approach with non-pharmacological and drugbased approaches to breathlessness is generally necessary, the latter predominating as death approaches. Further research on the management of breathlessness may supplement the currently limited evidence base.

\section{Conflicts of interest}

There are no known conflicts of interest relating to this article.

\section{References}

1 Moody LE, Webb M, Cheung R, Lowell J. A focus group for caregivers of hospice patients with severe dyspnea. Am J Hosp Palliat Care 2004;21:121-30.

2 Dudgeon DJ, Lertzman M. Dyspnea in the advanced cancer patient. J Pain Symptom Manage 1998;16:212-9.

3 Ahmedzai SH, Shrivastav SP. Breathlessness. Medicine 2004;32:14-6.

4 Wilcock A, Crosby V, Hughes A, Fielding K et al. Descriptors of breathlessness in patients with cancer and other cardiorespiratory diseases. J Pain Symptom Manage 2002;23:182-9.

5 Chan KS, Sham MM, Tse DM, Thorsen AB. Palliative medicine in malignant respiratory diseases. In: Doyle D, Hanks G, Cherny N, Calman K (eds). Oxford textbook of palliative medicine, 3rd edn. Oxford: Oxford University Press, 2004:587-618.

6 Maher D, Hemming L. Palliative care for breathless patients in the community. Review. Br J Community Nurs 2005;10: 414-8. 
7 Sonnenblick M, Melzer E, Rosin AJ. Body positional effect on gas exchange in unilateral pleural effusion. Chest 1983;83:784-6.

8 Filshie J, Penn K, Ashley S, Davis CL. Acupuncture for the relief of cancer-related breathlessness. Palliat Med 1996;10:145-50.

9 Bredin M, Corner J, Krishnasamy M, Plant $\mathrm{H}$ et al. Multicentre randomised controlled trial of nursing intervention for breathlessness in patients with lung cancer. BMJ 1999;318:901-4.

10 Hately J, Laurence V, Scott A, Baker R, Thomas P. Breathlessness clinics within specialist palliative care settings can improve the quality of life and functional capacity of patients with lung cancer. Palliat Med 2003;17:410-7.

11 Booth S, Wade R, Johnson M, Kite S et al. The use of oxygen in the palliation of breathlessness. A report of the expert working group of the Scientific Committee of the Association of Palliative Medicine. Review. Respir Med 2004;98:66-77.

12 Pauwels RA, Buist AS, Calverley PM, Jenkins CR, Hurd SS; GOLD Scientific Committee. Global strategy for the diagnosis, management, and prevention of chronic obstructive pulmonary disease. NHLBI/WHO Global Initiative for Chronic Obstructive Lung Disease (GOLD) Workshop summary. Review. Am J Respir Crit Care Med 2001;163:1256-76.

13 Muers MF. Opioids for dyspnoea. Thorax 2002;57:922-3.

14 Jennings AL, Davies AN, Higgins JP, Gibbs JS, Broadley KE. A systematic review of the use of opioids in the management of dyspnoea. Thorax 2002;57:939-44.

15 Allen S, Raut S, Woollard J, Vassallo M. Low dose diamorphine reduces breathlessness without causing a fall in oxygen saturation in elderly patients with end-stage idiopathic pulmonary fibrosis. Palliat Med 2005;19: 128-30.

16 Ahmedzai S, Davis C. Nebulised drugs in palliative care. Thorax 1997;52(Suppl 2): S75-7.

17 Shee CD. Palliation in chronic respiratory disease. Review. Palliat Med 1995;9:3-12.

18 Kohara H, Ueoka H, Aoe K, Maeda T et al Effect of nebulized furosemide in terminally ill cancer patients with dyspnea. J Pain Symptom Manage 2003;26:962-7.

19 Ong KC, Kor AC, Chong WF, Earnest A, Wang YT. Effects of inhaled furosemide on exertional dyspnea in chronic obstructive pulmonary disease. Am J Respir Crit Care Med 2004;169:1028-33.

\section{The principles of cancer pain management}

Marie Fallon MD FRCP(Glas) FRCP(Ed) MRCGP, Reader in Palliative Medicine, University of Edinburgh, Edinburgh Cancer Centre, Western General Hospital, Edinburgh

Sandra McConnell MB ChB MRCP, Specialist Registrar in Palliative Medicine, Western General Hospital, Edinburgh

\section{Clin Med 2006:6:136-9}

Pain occurs in up to $70 \%$ of patients with advanced cancer and in about $65 \%$ of patients dying from non-malignant disease. Pain can be controlled in most (about 80\%) using a simple, stepwise approach and a limited number of analgesics as set out in the World Health Organization (WHO) analgesic ladder (Fig 1). ${ }^{1}$ The severity of the pain dictates the strength of analgesic and the pathophysiology dictates the adjuvant analgesic to be prescribed.

About $10 \%$ of patients will require more complex, sometimes invasive, management to control their pain, leaving another $10 \%$ with cancer pain that is difficult to control.

\section{Assessment of pain}

The keystone to successful management is assessment which should reveal:

- patient characteristics, including mood

- pain characteristics

- drug responsiveness.

\section{Patient characteristics}

Characteristics relating to the patient are:

- previous problems with analgesia

- fear of opioids

- deranged biochemistry, and

- mood.

Assessment of mood in a patient with uncontrolled cancer pain should be made with an open mind. If depressed, patients

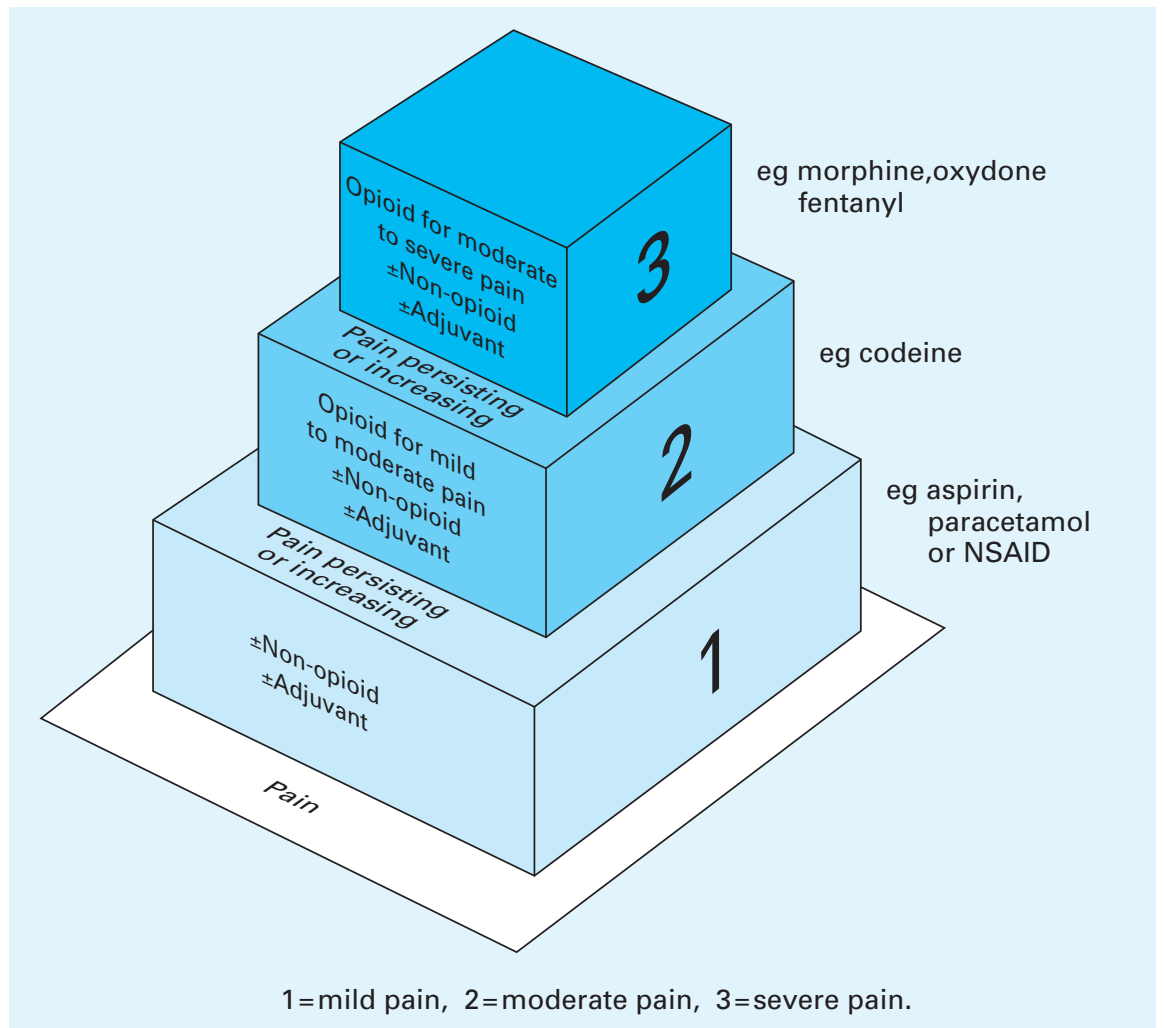

Fig 1. World Health Organization three-step analgesic ladder. NSAID = non-steroidal anti-inflammatory drug. ${ }^{1}$ 